\title{
TEMPORALITY REVISTED: KIERKEGAARD AND THE TRANSITIVE CHARACTER OF TIME
}

FRANK SCHALOW

Loyola University, New Orleans

One of the precautions that people are beginning to take seriously in interpreting Kirkegaard's writings is not to identify too quickly his own position with that which is expressed under the pseudonymous authorship of any of his works. 1 But there is a parallel trap which, while somewhat subtler in form, must also be avoided to prevent serious misunderstanding. Specifically, the danger arises that the initial neglect can easily spill over into attributing to him a critique of a counter position which he never really opposed. The purpose of this essay is to address one special case where such a dual confusion originates; it involves one of the most central topics in all of Kierkegaard's works, namely, the interpretation of time as it questions the very possibility of the self's conversion. This interpretation is found in The Concept of Dread. 2

The point of ambiguity which needs to be exposed stems from not distinguishing between what Kierkegaard would hope to accomplish through his discussion of time and how he raises that issue in a context which initially supports a more "conventional" stance. From the many different allusions Kierkegaard makes, one would assume that he challenges a simplistic view of time as a "succession of nows," and hopes to arrive at, by way of contrast, a more sophisticated position which can mark the convergence between the temporal and eternal as the cornerstone for religious conversion. But while the assessment of his "mature" position may be correct, how he ultimately comes to it and what he opposes remains rather vague. Indeed, we attribute too much to Kierkegaard himself if we maintain that he substitutes his own "existentially" clarified concept of time for a derivative view of the same, of time as a linear series of moments which is inherited from the philosophical tradition. By drawing this contrast too sharply, by pitting a position held by Kierkegaard against one held by his "opponent," we would package his view of time in too ontologically pure distinctions. While these may be especially important to his successors, they prove completely foreign to the concerns originally provoking his inquiry.

1 Cf. Kierkegaard, The Point of View for My Works as An Author, trans. David F. Swenson and Walter Lowrie (Princeton: Princeton University Press, 1941), pp. 537-539.

2 Kierkegaard, The Concept of Dread, trans. Walter Lowrie (Princeton: Princeton University Press, 1944), pp. 74-83. 
Unless we outline the context of Kierkegaard's analysis of time, we risk effacing the boundary separating him from the subsequent tradition of existentialism and hermeneutic phenomenology. 3 This tradition seizes upon the issue of time as one of its most cherished themes. Specifically, a neglect for Kierkegaard's sympathetic way of treating the "conventional" view of time, of his dexterity in not characterizing it as "inferior" and polarizing it with his own, leads to the belief that he is on the way to a "radicalized" account of temporality. This is the vision of time as having a cyclical or elliptical form which decisively overturns the linear model that was pioneered in certain respects by Aristotle. 4

Needless to say, both Heidegger and current scholars of his thought, as well as those of a "post-modern" bent, have read Kierkegaard as pointing the way to a more dynamic view of time which can offset the dangers of a "metaphysical" allegiance to the "present," even to the point of viewing him as a forerunner to the "deconstructionist" overthrow of "congealed presence." 5 By contrast, this paper contends that Kierkegaard does not necessarily reject the conventional view of time as a succession of moments; instead he allows it to play a factor in his attempt to question the interdependence of present, future, and eternity as a kind of transitive relation rather than as a movement exhibiting the circularity of interpretation.

In developing this argument, I will first mark the source of the tendency to bring Kierkegaard into the existentialist-hermeneutical camp, while identifying the context in his writings whose careful consideration would allow us to address "his" insights on time. Second, I will spell out what constitutes the "transitivity" of time, thereby preserving the integrity of Kierkegaard's analysis apart from the interpretation sought by various proponents of Continental thought.

\section{The Paradox of Self-Identity}

Throughout the philosophical tradition, from Aristotle, to St. Augustine to Kant, and even up into the contemporary period, the issue of time has been inextricably interwoven with both cosmology and ontology. In a way that is not surprising but has never been fully appreciated, Kierkegaard does not explicitly begin from this background. Yet, his situation is complicated by the fact that theology, whose concern he voices

3 Cf. Frank Schalow, "Dread in a Post-Existentialist Era: Kierkegaard Reconsidered," The Heythrop Joumal, Vol. XXX, No. 2 (April 1989), pp. 160167.

4 Heidegger, Kant and the Problem of Metaphysics, trans. James C. Churchill (Bloomington: Indiana University Press, 1962), pp. 247-255.

5 Cf. John D. Caputo, Radical Hermeneutics (Bloomington: Indiana University Press, 1987), pp. 11-35. 
in one way or another, has its own version of cosmology. Theology also proposes a corollary view of the "person" who, while created by God, later falls prey to $\sin$ and eventually shoulders the burden of a nature divided between "soul and body."6 Part of Kierkegaard's ingenuity is that he can acknowledge this portrayal, adopt its implicit anthropology, and yet accentuate different facets of it in a way that reveals an alternative side to the stereotypical vision of the world and of the selfs place within it.

Specifically, the theological version tends to view the human predicament as an outgrowth of cosmic forces with an element of necessity to it. Rather than voicing the metaphysical-cosmic question "why?", Kierkegaard instead appeals to the initiative that the individual himself can muster to confront the painful conflict at the heart of existence. No doubt the fact that the self exists temporally surrounds this conflict, particularly in view of what Christian cosmology upholds as one's "eternal," Divine destination. For Kierkegaard, what becomes relevant is not the why or wherefore of human being's temporal condition, but rather the demands and opportunities it presents on the pathway to achieving true selfhood.

It is either too presumptuous or too trivial to suggest that Kierkegaard addresses the issue of time within a Christian context. For him, what is really important is how the crisis that is endemic to Christianity can ascend into the forefront of human concern, that is, what is the "potentiality" which the individual possesses in order to be equal to the challenge posed by religious faith. Kierkegaard refers to this potentiality as "spirit."7 Yet, in a way that may be somewhat different than both Christian cosmology and anthropology, spirit is not itself to be defined as something "higher" vs. something "lower," as one side of an antithesis or of a later synthesis. Instead, spirit already encompasses any tension that can combine opposite terms. For Kierkegaard, it is not because man has been created to experience such a tension that he finds himself suspended between two conflicting poles of existence; it is rather the case that spirit already provokes in man a concern for the apex of his existence, thereby allowing him to experience such a tension, that is, find himself capable of being torn asunder. Thus, man is not born with an "innate" sense of his dualistic nature, anymore than he is "born a Christian."8

The emphasis which Kierkegaard places on potentiality and the selfs engagement with possibilities has certainly lured subsequent

\footnotetext{
6 Kierkegaard, The Concept of Dread, p. 39.

7 I bid., p. 39.

8 Kierkegaard, Concluding Unscientific Postscript, trans. David F. Swenson and Walter Lowrie (Princeton: Princeton University Press, 1941), Pp. 537-539.
} 
thinkers into seeking clues to a more radicalized conception of human existence. Yet the majority of these efforts, most noticeably Heidegger's, have labored under the assumption that this potentiality becomes meaningful only when it is linked with what can mark the definitive structure of human existence, namely, finitude.9 There remains a tendency to expect an ontological followup to Kierkegaard's legacy, to the demands of philosophical discourse. Consequently, there is a danger of forgetting that existence cannot be abstractly defined apart from the changes it undergoes, since it is these changes which render existence meaningful rather than the reverse.

As is well known, the individual's transformation takes a religious form. To undergo this dramatic change, the self must be delivered from its oscillation between happiness and despair, and discover that its wholeness is achieved not piecemeal via specific efforts but all at once through its dependency on the Divine. In a way that may escape the ontological thrust of subsequent thinkers, Kierkegaard views possibility, the animating power of existence, as already chiseled with the features of the selfs development in the highest sense, as already drawn in the direction of exaltation. And yet that direction becomes clear only to the extent that the self has simultaneously acknowledged the option to move in precisely the opposite way. The individual entertains these options together, positing them at once; only by ascribing to this ambivalence can the self monitor its own transition to a higher state, the very path to realizing its identity or achieving selfhood.

On the surface, Kierkegaard seems to suggest that the self undergoes a process of maturation from a non-religious to a religious state, a process which entails a temporal scheme between "earlier" and "later." For him, the issue of time is intimately interwoven into a concern for the ultimate spiritual destiny of the self.10 But precisely here lies the importance of carefully assessing the emphasis that Kierkegaard places on pseudonymous authorship, both in respect to his position and that which he presumably would counter. For him the issue of time is prominent but it is not necessarily to be thematized in a way that admits a polarity of stances according to some preset program of ontology. The fact that the self is defined by its own development implies time; however, that development is one whose meaning is gauged from the standpoint of eternity. Insofar as eternity and time converge to mark the selfs transformation, the status of the temporal is dramatically thrown into question. Despite this interrogative spirit, Kierkegaard does not abruptly

9 For a lucid adaptation of Kierkegaard in Heideggerian terms, see Michael E. Zimmerman, Eclipse of the Self (Ohio: Ohio University Press, 1981), pp. 135-149.

10 Roy Martinez, "Kierkegaard's Ideal of Inward Deepening," Philosophy Today, Vol. 32, No. 2 (Summer, 1988), p. 113. 
dismiss the conventional view of time, but instead seeks to preserve its character although with a slightly different emphasis:

So, then, man was said to be a synthesis of soul and body; but he is at the same time a synthesis of the temporal and the eternal. I have no objection to recognizing that this has often been said; I have no wish to discover novelties, but rather it is my joy and my darling occupation to think upon things which seem perfectly simple.11

Subsequent thinkers have not taken Kierkegaard at his word. Acutely aware of the above paradox of individual identity, they have reasoned that in order to accommodate the impact which eternity has on the spiritual development of the self, Kierkegaard must challenge the traditional view of time as a succession of moments. Given the logic of this argument, its precedent inevitably resides in Kierkegaard's penetrating analysis of "repetition." There he emphasizes the self's need to appropriate previous possibilities and continually to renew its own way of choosing itself or of making commitments. The inescapable importance of this account, when combined with the prior assumption that Kierkegaard challenges the traditional view of time (i.e., in a linear sense), provides all the ammunition necessary to propose a novel interpretation of temporality as an elliptical movement integrating all the dimensions of time-past, present, future--in a dynamic way. This small step, or extrapolation if you will of distinguishing Kierkegaard's position from that of his alleged opponent, proves to be all that is needed for Heidegger to associate Kierkegaard with his own version of primordial, ecstatic temporality. 12

To be sure, the elliptical view of temporality proves advantageous as a way of explaining the relation between time and eternity. According to this view, the eternal and the temporal are no longer to be opposed, which is inevitable so long as we identify time with a disjointed succession of moments. Instead, the movement of repetition demands that past possibilities are rediscovered in the future, thereby creating a tension between the extreme dimensions of time which together elicit the "present" in a dynamical way. As the juncture where a new level of meaning arises, the present then consolidates all the disjointed points of time so as to harbor within itself the very face of eternity. When interpreted in this light, Kierkegaard's idea of repetition suggests the selfconstituting process of time which includes an impetus apart from merely

11 Kierkegaard, The Concept of Dread, p. 76.

12 Heidegger, Being and Time, trans. John Macquarrie and Edward Robinson (New York: Harper \& Row, Publishers, Inc., 1962), pp. 434-439. 
chronicling events in sequential order. Even if one still subscribes to an otherworldly view, eternity proves relevant only insofar it partakes of the tension which joins the respective dimensions of "temporality" in their relation with one another.

In seeking in Kierkegaard's writings the pattern for a radicalized view of temporality, the existential-hermeneutical approach implicitly tilts its interpretation to the side of finitude. Eternity thereby becomes something of a subset of temporality, to be purged of its otherworldly demeanor. Yet regardless of whether we judge this interpretation to be fair or overly "creative," from our standpoint it proves to be symptomatic of an indifference to the intricacies of Kierkegaard's method. The true danger does not lie simply in obscuring the infinite for the sake of recovering temporality as the root of "Being-in-the-world." Instead, the difficulty is one of assuming that the position that Kierkegaard allegedly rejects is not itself a part of the self's experience of time which reserves for itself a certain proximity with eternity. Put simply, for Kierkegaard it is not as though there are two different versions of time, one originary or "primordial" and the other derivative or "fallen." 13 There is only time itself and the way in which the selfs' transformation demands its participation in eternity.

As we will see in the next section, Kierkegaard faced some difficulty in determining how to "express" this peculiar facet of time. But the vagueness and the ambivalence we find in his writings on this topic, particularly in The Concept of Dread, should not necessarily be taken as an invitation to seek further clarity by polarizing two competing versions of time. Rather, it should be a warning to us to take more seriously the intent of his method in employing a pseudonymous authorship. Given this observation, let us then return to the key passages in the The Concept of Dread where "Vigilius Haufniensis" addresses the unique character of time. We will discover that it has more the character of "transitivity" than the elliptical nature favored by contemporary hermeneutics.

\section{Eternity and Succession}

Through his view of time, Kierkegaard responds to the quandary posed by the selfs existence. The self is beset by a concern for its own identity, in such a way that the very attempt to arrive at a solution through its own powers thwarts the desired goal. Undoubtably a parallel can be drawn between Kierkegaard's approach to this question and the hermeneutical consideration of "authenticity." But once again the impact of tilting the latter discussion in the direction of finitude becomes apparent. For in Heidegger's case, at least, authentic existence is intimately connected with the individual's seizing hold of mortality as his

13I bid., pp. 375-382. 
"ownmost possibility"; time is thereby defined through the priority of a future whose finality provokes a regard for the selfs own limitations. 14

To be sure, Kierkegaard resists this vision of time as radically finite. Yet his reservation does not distinguish what is problematic in that approach. Indeed, where he stands on the issue of infinite vs. finite is vital, but even more important is how his approach secures a definitive "goal" for human existence. The difficulty in elevating a single possibility (e.g., death) over all others is that it restricts the selfs choices to what already lies within its power; no room is left for the additional requirement of discrimination which comes from specifying a particular goal. What would pose the greatest challenge to choice, namely, a "dilemma," can arise only indirectly as an offshoot of finitude. As a result, the sharpened edge of ethical decision-making becomes dulled, leaving ethics to flounder in a way which Heidegger scholars have recently come to recognize.15 By taking as his point of departure the uniqueness of the Christian experience, Kierkegaard can elicit clues to the actual formation of self-identity, to the temporal character of the self. These clues serve to outline a definitive ethical stance.

We cannot underestimate the importance that ethics plays in Kierkegaard's quest to illuminate the character of time. For it is not the desire to make time the axis of an ontology that defines his investigation. Quite the reverse, he asks how the selfs awakening to its ethical character can allow us to ponder the ambivalency of human existence in its most concrete, i.e., temporal setting. Inherent in this setting is the emotion which can arouse the self from its slumber of indifference, exposing at once the degree of the individual's ineffectiveness in producing his own happiness and one's "power" of being able to choose as the prerequisite for spirituality. The mood in question, of course, proves to be "dread," which holds forth the self at the threshold of its transition from despair to salvation. 16

Kierkegaard suggests that the self endures the tension of crossing this threshold through its ethical posture. For in facing an ethical dilemma, the self discovers that it is already part of a relation, of a "synthesis" which suggests a further stage of development than where it currently "is."17 Ethics addresses this stage of development and points to the perfection of the self on a higher plane than where it now exists. But

\section{Heidegger, Being and Time, p. 309.}

15 Cf. Charles E. Scott, "Heidegger and the Question of Ethics," Research in Phenomenology, Vol. XVIII (1988), pp. 23-40.

16 Kierkegaard, The Concept of Dread, p. 40.

17 Cf. C. Stephen Evans, Kierkegaard's Fragments and Postscript: The Religious Philosophy of Johannes Climacus (Atlantic Highlands: Humanities Press, 1983), p. 41. 
precisely in acknowledging the possibility of this spiritual ascent, Kierkegaard simultaneously poses a problem as to the actual "identity" of the self. For the person only becomes who he is once having transferred the focus of concern away from a narrow preoccupation with his desires (spawning despair) to that higher source or "third something" that can sustain his existence. But even prior to this fulfillment there is a question as to the period in which the self is ignorant of its identity, an essential skepticism of not knowing even what is at stake in addressing one's personhood. The individual so completely masks his identity as to be unable to supply a focus for the search.

In posing this enigma of the self s identity, Kierkegaard turns to a discussion of time. Needless to say, his discussion is not as straightforward as one might hope, but is presented more as a "puzzle" in a way reflecting a certain inscrutability about the self. The delicacy with which Kierkegaard addresses time comes to light in an innocuous distinction that is quite easily overlooked. Specifically, he seeks a different connotation for the present in the guise of the "instant." 18 For him, the instant is not merely a convenient synonym, but instead marks the way in which the present can concretely stand in direct contrast with its opposite, namely, duration. The point of this contrast is not to show the mutual exclusivity of the eternal and the temporal, but, quite the reverse, to amplify what is distinctive of the "present" 80 as to mark its intersection with eternity. 19 This intersection will then become the new haven for the "ambiguity" which characterizes the selfs transition to spiritual fulfillment.

If the self is in a period of transition, then what it requires to discover its identity is the alteration of the (fleeting) present into some semblance of permanence. This "duration" requires a peculiar complementarity between eternity and time, through a synthesis parallel to that which defines the self. "The synthesis of the eternal and temporal is not a second synthesis but is the expression for the first synthesis in consequence of which man is a synthesis of soul and body sustained by spirit."20 The ensuing stability, however, is not born from the cessation of strife, but instead marks the beginning of the selfs concern and only thus has the character of "eternity." But what exactly does this mean? Insofar as eternity is inclusive of everything, of all segments of time, the efficacy proper to it must be implicitly transmitted to the present as well. In this respect, the present is potentially eternal. Accordingly, the eternal character of the present amounts to a change in the quality and richness of whatever one experiences in it. Kierkegaard summarizes the matter this

18 Kierkegaard, The Concept of Dread, Pp. 78-80.

19 Martinez, Kierkegaard's Ideal of Inward Deepening, Pp. 115-116.

20 Kierkegaard, The Concept of Dread, p. 79. 
way: "The present is the eternal, or rather the eternal is the present, and the present is full." 21

By the same token, eternity is not something which has already happened and is isolated from experience. It is not to be opposed to the temporal, even time understood as a succession of moments. Indeed, eternity acquires its meaning precisely because it can embody (given the underlying effect of dread) 22 that which grants to the individual the very capacity for choice, namely, freedom itself. The eternal does not entail repose, but rather involves the discharging of possibilities that directly determine the selfs ultimate development. From the standpoint of this development, however, possibilities arise from the future. Thus, Kierkegaard suggests that the "future is eternity."

In making this division, attention is at once drawn to the fact that in a certain sense the future signifies more than the present and the past; for the future is in a sense the whole of which the past is a part, and in a sense the future may signify the whole. This is due to the fact that the eternal means first of all the future, or that the future is the incognito in which the eternal, as incommensurable for time, would nevertheless maintain its relations with time. Thus we sometimes speak of the future as identical with eternity: the future life = eternal life.23

In drawing this equivalence, Kierkegaard establishes the relation which gives the best clue to his understanding of time.

To adopt this clue, it is necessary to join the two extreme terms which have only been indirectly linked by the "middle," the future and the present. That connection cannot be made by logical equivalency, however, but must instead be drawn from experience itself. In other words, as the temporal dimension defining the contingencies of the selfs existence, the present becomes the site for the enactment of all those possibilities which mark its spiritual development and its eventual exaltation toward the Divine. The present thereby defines time essentially, but not by itself; it instead does so by yielding to the future, thereby becoming the transposed fulcrum in which the self exchanges the contingencies of its desires for the necessity of its commitment.

Thus, to draw out the threefold character of time, or its essential "transitivity," we can say that the present is eternity because it is sustained

21 Kierkegaard, The Concept of Dread., pp. 77-78.

22 Cf. Schalow, "Dread in a Post-Existentialist Era," p. 163.

23 Kierkegaard, The Concept of Dread, p. 80. 
by that movement which lends a certain direction to the eternal, namely, the future. In marking the covergence of all moments, the future resonates with eternity by defining the fulfillment of the self in each of its possibilities. Only through this description can we ultimately arrive at the central tenet of Johannes Climacus' view of conversion expressed in the Philosophical Fragments, the breakthrough of the eternal in time as the prerequisite for the disciple becoming "contemporaneous" with Christ. 24 Given the adequacy of our interpretation, we find that in The Concept of Dread time assumes a transitive character in which the significance of each of its facets depends upon its subsequent relation to the other. This transitivity defines what is most unique to Kierkegaard's discussion of time, in contrast to its alleged similarity to the elliptical pattern of temporality upheld by hermeneutics.

If there is any loose thread which still needs to be tied, it surely lies in addressing the relevance of the "past." 25 But the easiest response to what might at first appear to be an omission in our discussion of Kierkegaard lies in recognizing that the "past" constitutes a separate problem in its own right and needs to be examined in another region of discourse (e.g., in considering the character of "repetition"). 26 Repetition points to the need for the renewal of those possibilities which have already been opened up through the future. But the permanence of that renewal does not depend upon any elliptical pattern of time; instead it is the impingement of the eternal in integrating the future and present together which demands the kind of stance toward the past which is found in repetition. Thus, the very merit of the "method" we have tried to follow, in contrast to the rather presumptuous demand for a unified ontology, lies in sanctioning a certain dissemination of insight that does not have to be integrated into a final doctrine. 27 The crucial avoidance of an initially

24 Kierkegaard, Philosophical Fragments, trans. David F. Swenson (Princeton: Princeton University Press, 1967), pp. 72-81.

25 Cf. Kresten Nordentoft, Kierkegaard Psychology, trans. Bruce H. Kirmmse (Pittsburgh: Duquesne University Press, 1978), pp. 131-135. Nordentoft suggests that at least within The Concept of Dread, Kierkegaard develops more of a "prospective" than a "retrospective" view of time. Whether or not we wish to characterize Kierkegaard's analysis as "psychological" remains open to question.

26 "Repetition" (Gientagelse) means "again-taking," and is to be contrasted with recollection in the Platonic Sense. Cf. Evans, Kierkegaard's Fragments and Postscript: The Religious Philosophy of Johannes Climacus, p. 154.

27 I credit Caputo for seeing this, as much as I disagree with his attempt to make repetition the focus of Kierkegaard's thought. 
misleading tendency by hermeneutics to adopt Kierkegaard as its precursor proves in the end to be the very point of exit for our discussion.

Perhaps one might still wonder how accurate it is to describe Kierkegaard's view of time as involving "transitivity." Yet my goal has not been to provide an "authoritative" interpretation, as much as to appreciate some of the nuances in Kierkegaard's account of time. Only through such attunement can we become open to what he intended us to experience as a renewal of the Christian message.28

28 I wish to thank Professor Roy Martinez of Spelman College for his direction in helping me to read Kierkegaard's enigmatic writings. 